\title{
SOME HARDY AND CARLESON MEASURE SPACES ESTIMATES FOR BOCHNER-RIESZ MEANS
}

\author{
JIAN TAN
}

Abstract. In this paper, we show that the Bochner-Riesz means are bounded on weighted and variable Hardy spaces by using the finite atomic decomposition theories. The boundedness of Bochner-Riesz means on weighted and variable Carleson measure spaces is also obtained. Moreover, we also prove that the maximal Bochner-Riesz means are bounded from weighted or vaiable Hardy spaces to weighted or variable Lebesgue spaces.

Mathematics subject classification (2010): 42B25, 42B30, 46E30.

Keywords and phrases: Bochner-Riesz means, Hardy spaces, Carleson measure spaces, weights, variable exponents.

\section{REFERENCES}

[1] K. F. ANDERSEN, R. T. John, Russel, Weighted inequalities for vector-valued maximal functions and singular integrals, Studia Math, 69, 1 (1980/81), 19-31.

[2] S. Bochner, Summation of multiple Fourier series by spherical means, Trans. Amer. Math. Soc., 40, (1936), 175-207.

[3] D. CruZ-Uribe And A. Fiorenza, Variable Lebesgue Spaces: Foundations and Harmonic Analysis, Birkhäuser, Basel, 2013.

[4] D. Cruz-Uribe, A. Fiorenza, J. Martell and C. Pérez, The boundedness of classical operators on variable $L^{p}$ spaces, Ann. Acad. Sci. Fenn. Math., 31, (2006), 239-264.

[5] D. Cruz-Uribe, J. Martell and C. PÉRez, Weights, extrapolation and the theory of Rubio de Francia, Birkhäuser, Basel, 2011.

[6] D. Cruz-Uribe, K. Moen and H. V. Nguyen, A new approach to norm inequalities on weighted and variable Hardy spaces, Ann. Acad. Sci. Fenn. Math., 45, (2020), 175-198.

[7] D. CRUZ-Uribe AND L. WANG, Variable Hardy spaces, Indiana Univ. Math. J., 63, 2 (2014), $447-$ 493.

[8] L. Diening, Maximal function on Musielak-Orlicz spaces and generalized Lebesgue spaces, Bull. Sci. Math., 129, 8 (2005), 657-700.

[9] L. Diening, P. Harjulehto, P. HÄStÖ And M. RŮŽIČKA, Lebesgue and Sobolev spaces with variable exponents, Springer, Heidelberg, 2011.

[10] J. DuoAndikoetxea, Fourier analysis, American Mathematical Society, Providence, RI, 2001.

[11] Y.-C. HAN, Y.-S. HAN, Boundedness of composition operators associated with mixed homogeneities on Lipschitz spaces, Math. Res. Lett. 23, 5 (2016), 1387-1403.

[12] Y.-C. HAN, Y.-S. HAN, J. LI, Geometry and Hardy spaces on spaces of homogeneous type in the sense of Coifman and Weiss, Sci. China Math., 60, 11 (2017), 2199-2218.

[13] Y.-C. HAN, Y.-S. HAN, J. LI, Criterion of the boundedness of singular integrals on spaces of homogeneous type, J. Funct. Anal. 271, 12 (2016), 3423-3464.

[14] Y.-C. HAN, Y.-S. HAN, J. LI, C.-Q. TAN, Hardy and Carleson measure spaces associated with operators on spaces of homogeneous type, Potential Anal. 49, 2 (2018), 247-265.

[15] Y.-S. HAN, J. LI, L. WARD, Hardy space theory on spaces of homogeneous type via orthonormal wavelet bases, Appl. Comput. Harmon. Anal. 45, 1 (2018), 120-169.

[16] M.-Y. LEE, Weighted norm inequalities of Bochner-Riesz means, J. Math. Anal. Appl., 324, (2006), $1274-1281$. 
[17] M.-Y. LeE, C.-C. Lin AND Y.-C. Lin, A wavelet characterization for the dual of weighted Hardy spaces, Proc. Amer. Math. Soc., 137, (2009), 4219-4225.

[18] J. LI, L. WARD, Singular integrals on Carleson measure spaces $C M O^{p}$ on product spaces of homogeneous type, Proc. Amer. Math. Soc., 141, 8 (2013), 2767-2782.

[19] S. Lu, Four Lectures on Real $H^{p}$ spaces, World Scientific Publishing, River Edge, N. J., 1995.

[20] E. NAKAI AND Y. SAWANO, Hardy spaces with variable exponents and generalized Campanato spaces, J. Funct. Anal., 262 (2012), 3665-3748.

[21] P. SJöLIn, Convolution with oscillating kernels in $H^{p}$ spaces, J. London Math. Soc., 23, (1981), 442-454.

[22] E.M. Stein, M.H. TAibleson, G. Weiss, Weak type estimates for maximal operators on certain $H^{p}$ classes, Rend. Circ. Mat. Palermo 2, (Suppl. 1), (1981), 81-97.

[23] J.-O. Strömberg, A. Torchinsk y, Weighted Hardy spaces, Lecture Notes in Mathematics, 1381. Springer-Verlag, Berlin, 1989.

[24] J. TAN, Discrete para-product operators on variable Hardy spaces, Can. Math. Bull., 63, 2 (2020), 304-317.

[25] J. TAN, Carleson measure spaces with variable exponents and their applications, Integral Equations Operator Theory, 91, 5 (2019), 91:38.

[26] J. TAn, Atomic decomposition of variable Hardy spaces via Littlewood-Paley-Stein theory, Ann. Funct. Anal., 9, 1 (2018), 87-100.

[27] J. TAN, Weighted Hardy and Carleson measure spaces estimates for fractional integrations, (2019), preprint.

[28] J. TAN, Y.-C. HAN, Inhomogeneous multi-parameter Lipschitz spaces associated with different homogeneities and their applications, Filomat, 32, 9 (2018), 3397-3408.

[29] H. WANG, Boundedness of Bochner-Riesz operators on weighted weak Hardy spaces (Chinese), Acta Math. Sinica (Chin. Ser.), 56, 4 (2013), 505-518.

[30] D. YANG, W. YUAN, C. ZHUO, A survey on some variable function spaces, Function spaces and inequalities, 299-335, Springer Proc. Math. Stat., 206, Springer, Singapore, 2017.

[31] D. YAng, C. Zhuo, E. NAKaI, Characterizations of variable exponent Hardy spaces via Riesz transforms, Rev. Mat. Complut., 29, (2016), 245-270.

[32] C. Zhuo, D. YAng, Y. Liang, Intrinsic square function characterizations of Hardy spaces with variable exponents, Bull. Malays. Math. Sci. Soc., 39, 4 (2016), 1541-1577. 